\title{
HYDROGEOLOGICAL INVESTIGATIONS IN THE BULAWAYO REGION, MATABELELAND, ZIMBABWE
}

\author{
Bodil Lorentzen ${ }^{1}$, Zodwa Dladla ${ }^{2}$, Patience Gwaze ${ }^{2}$ \\ Torleif Dahlin ${ }^{3}$, and Niels B. Christensen ${ }^{1}$ \\ 1) Department of Earth Sciences, University of Aarhus \\ Finlandsgade 8, DK-8200 Aarhus N, Denmark \\ 2) Department of Geology, University of Harare, Zimbabwe \\ 3) Lund Technical University, Department of Technical Geology \\ Box 118, 22100 Lund, Sweden
}

\begin{abstract}
INTRODUCTION
Within the framework of hydrogeological studies for additional water supply for the city of Bulawayo, Zimbabwe, a cooperation between the University of Zimbabwe, Lund Technical University, Sweden, and the University of Aarhus, Denmark, with support from the Swedish International Development Agency has led to a geophysical survey of the large Kalahari and Karoo sedimentary basins in North Matebeleland, for the purpose of assessing water resources. The City of Bulawayo suffers from insufficient water supplies which in drought years becomes aggravating. In an attempt to alleviate this, the Bulawayo Matebeleland Zambezi Water Supply Feasibility Study has been carried out. This study concluded that groundwater appears to represent a very important component of the short to medium term affordable augmentation of Bulawayo's water supply. These conclusions are drawn from results of test pumping of existing deep wells along the Bulawayo Victoria Falls Railway. On a regional scale, gravity and aeromagnetic data combined with studies of boreholes yields and Landsat lineament were used to determine the structure and margins of syn-sedimentary sub-basins. Next, a number of favorable areas were selected for detailed profiling with the Transient Electromagnetic method (TEM) to locate accurately the fractured zones and the aquifer structure in the sedimentary basins, targets for exploratory drillholes. One of the locations selected is the Sawmills area, where NRZ (National Railway of Zimbabwe) has developed some very productive artesian wells ( 80 $\mathrm{m}^{3} / \mathrm{h}$ ) in the Karoo deposit (Owen, 1995).
\end{abstract}

\section{GEOLOGICAL SETTING}

Sawmills is the name of a station on the railway line from Bulawayo to Victoria Falls located $100 \mathrm{~km}$ WNW of Bulawayo in the Middle Zambezi Basin in the Karoo system. The Karoo era was initiated in late Carboniferous to early Permian times. Sedimentation continued throughout the Permian and Triassic to be brought to a close by vast fissure eruptions of mafic lava in the Lower Jurassic (Stagman, 1978).

The information on the Karoo rocks below the basalts was obtained from three closely spaced deep boreholes around Sawmills Station, the depths being 248,332 and $412 \mathrm{~m}$ (Bond and MacDonald, 1962). A thin veneer of Kalahari sediments (0-10 m) overlies Jurassic plateau basalts varying in thickness from 20-100 m (MacDonald, 1970). Thereafter the geology passes from Upper Karoo to Lower Karoo sediments bottoming on Basement Complex phyllites at $380 \mathrm{~m}$. 
The Kalahari system is of Tertiary age and consists of redeposited sands with overlying Pleistocene erosion surfaces and gravels with Stone Age artifacts. The Kalahari sand is a pink or buff colored structureless aeolien sands. There is a high proportion of fine dust.

The Upper Karoo is sandstones and mudstones interbedded. The sediments are a suite of unmetamorphosed, generally moderately consolidated sediments, ranging from fine argillaceous through to coarse arenaceous members.

Lower Karoo consists of grits, sandstones, carboniferous shales and coal stringers interbedded (Harrison, 1977). The lowest member in the Lower Karoo system is the Dwyka Glaciation. The deposit consists of chaotic gravels and boulder beds deposited in irregularities in the pre-Karoo floor, plus reworked tills and in many instances accumulations of varved clays with drop stones. On the evidence of the boreholes drilled at Sawmills the thickness of the tillite and a veneer of verved mudstone is approximately 50 $\mathrm{m}$, but the member thickness varies significantly over short distances. The Dwyka series is generally placed at lower Carboniferous position on the Palaeozoic polar wander curve for Africa (Stagman, 1978). This deposit has a very low resistivity and thanks to that the TEM method is very effective for mapping the basements of aquifers in the Sawmills area.

\section{DATA COLLECTION AND INTERPRETATION}

The equipment used in this survey is the PROTEM 57 TEM system from Geonics Limited. 62 measurements with an $80 \times 80$ central loop configuration have been made along the Buda $\mathrm{C}$ line $4 \mathrm{~km} E$ of Sawmills. The profile was of $12 \mathrm{~km}$ length with around $200 \mathrm{~m}$ spacing between soundings. Data have been recorded in the time interval from 100 $\mu \mathrm{sec}$ to 2-3 msec

The data have been interpreted with one-dimensional models with the electromagnetic inversion program SELMA (Simultaneous Electromagnetic Layered Modeling and Analysis) (Christensen and Auken, 1992) using a three-layer model, a four-layer model with a high surface resistivity of the initial model (model 1), and a four-layer model with a well conducting first layer (model 2 ). Data uncertainty was estimated to $5 \%$ for all data. The inversion was carried out with the $\mathrm{L}_{2}$-norm, i.e. as a least squares iterative inversion.

\section{RESULTS}

The results of the interpretations are seen in Figure 1 as model sections of concatenated $1 \mathrm{D}$ inversions.

The three-layer model section shows a high resistivity surface layer varying in thickness between $2 \mathrm{~m}$ and $35 \mathrm{~m}$. At profile coordinate $5100 \mathrm{~m}$ and $7250 \mathrm{~m}$ a thin low resistivity first layer is seen. The second layer is rather homogeneous with a resistivity around $50 \Omega \mathrm{m}$. The well conducting bottom layer lies around $10 \Omega \mathrm{m}$ at a depth which varies along the profile from $180 \mathrm{~m}$ to $120 \mathrm{~m}$ with a maximum around profile coordinate $7300 \mathrm{~m}$. The residuals of the final models were generally low and data were well fitted.

The model section obtained with the four-layer model 1 is rather similar to the threelayer model section, but with two top layers with high resistivities. At profile coordinates $5100 \mathrm{~m}$ and $7250 \mathrm{~m}$ the layer is a very thin veneer or has totally disappeared. The residual of the final models were generally low with a few exceptions and data were well fitted.

The model resulting from using the four-layer model 2 as initial model results in a section with a conductive overburden underlain by a high resistivity layer. The third layer has a resistivity very close to the one resulting from model 1 as initial model, and the depth to the good conductor shows the same variation, thought there are minor differences, 
especially around $6600 \mathrm{~m}$ where the depth to the good conductor is smaller. Data were all fitted well with a residual of the same magnitude as for model 1.
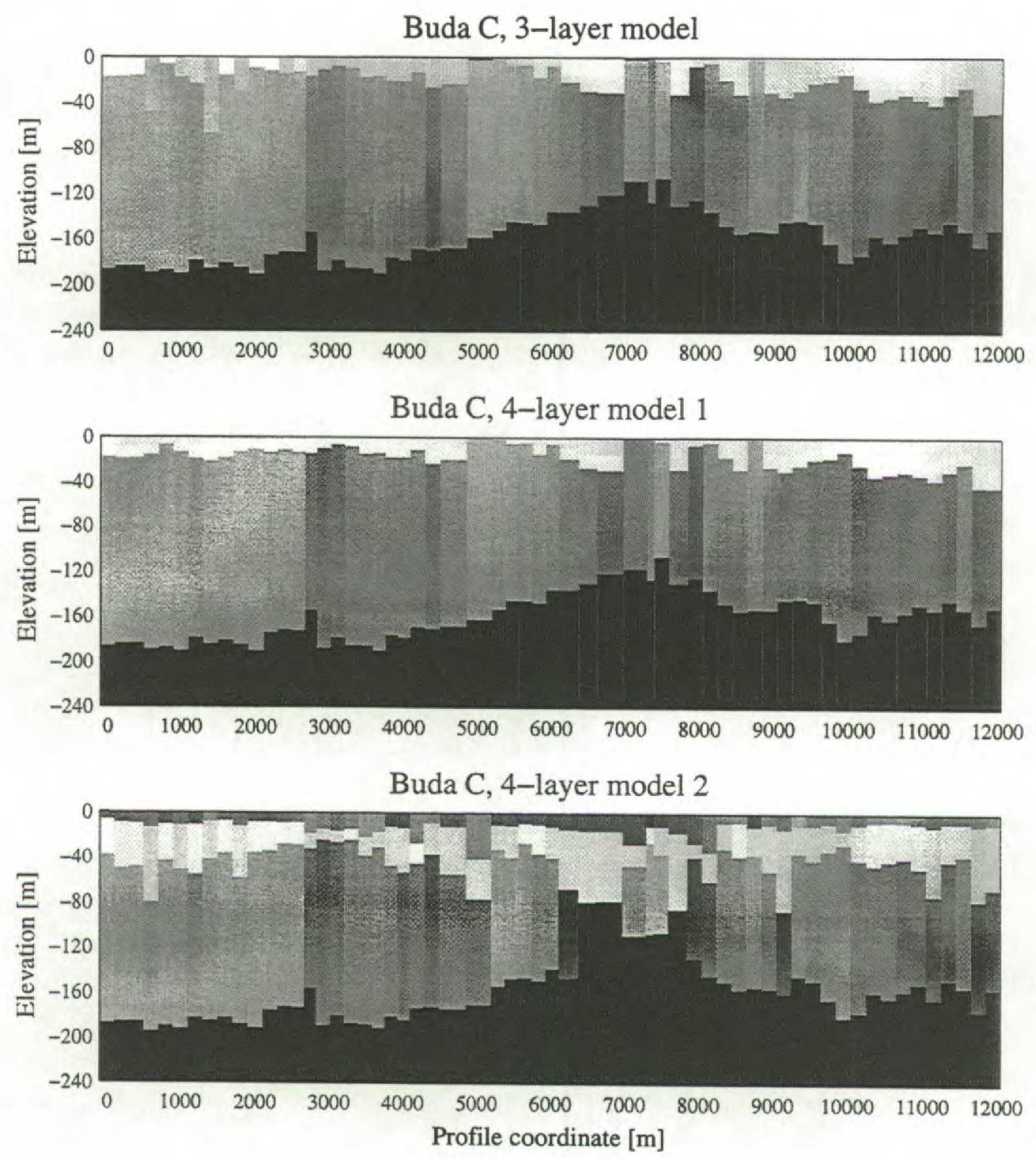

Figure 1: Model sections from a $12 \mathrm{~km}$ long profile, measured along a line with a $N N E$-SSW direction $4 \mathrm{~km} E$ of Sawmills, using a three-layer model (top) and two fourlayer models with different initial models. In the top section the initial model had the resistivities (from top): $200 \Omega \mathrm{m}, 50 \Omega \mathrm{m}$, and $10 \Omega \mathrm{m}$, and the thicknesses: $20 \mathrm{~m}$ and $150 \mathrm{~m}$. In the middle section the initial model had the resistivities: $500,1000,50$, and $10 \Omega \mathrm{m}$, and the thicknesses 30,30 , and $40 \mathrm{~m}$. In the bottom section the initial fourlayer model had the resistivities 30,200,50, and 10 $\mathrm{m}$, and the thicknesses 10,20, and $100 \mathrm{~m}$. The gray scale is linear in conductivity with white corresponding to $0 \mathrm{~S} / \mathrm{m}$ and black to $0.0667 \mathrm{~S} / \mathrm{m}$.

Comparing the results obtained for the three different models we see that they all arrive at a good conductor at depth and with similar depth profiles. This is in accordance with the fact that these parameters appear well determined from the analyses of the uncertainty of the model parameters. However, since the two different four-layer interpretations give 
different results concerning the top layers, it can be concluded that the data do not contain decisive information about the top $20 \mathrm{~m}-30 \mathrm{~m}$. This is confirmed by the analyses of the uncertainty of the model parameters. The resistivities of the two top layers and their thicknesses are undetermined for both interpretations. For the three-layer model the resistivity and thickness of the first layer is equally undetermined. The thickness of the 50 $\Omega \mathrm{m}$ layer above the substratum is generally undetermined, while the resistivity is poorly determined for the four-layer models and better determined for the three-layer model. With no borehole logging information on the profile line it is difficult to decide which model section should be preferred.

The high resistivity layer(s) that appears in the three-layer model and the four-layer models is most probably the Upper Karoo basalt. The layer with a resistivity of $50 \Omega \mathrm{m}$ is according to borehole data the Upper Karoo sandstone. The bottom layer with the very low resistivity is the Lower Karoo sedimentary formation. A deep testpumping at profile coordinate $220 \mathrm{~m}$ with a depth of $320 \mathrm{~m}$ (MacDonald, 1970) showed that the water quality is notable in that it is very low in hardness and chlorides, but fairly high in alkalinity which causes a high pH value of 9 (Owen, 1995). This explains the very low resistivity and is probably caused by the organic carbonaceous shales in the Upper Karoo formation.

\section{CONCLUSION}

The pre-feasibility study proved that the effective porosity in the Karoo formation lies between 1 and $10 \%$ (Owen, 1995), and since the Karoo sediments are known to be of the order of $300 \mathrm{~m}$ thick and extend over several thousand square kilometers, the inference is that very large volumes of water are stored in the Karoo sedimentary formations. The borehole testpumping confirmed that it is possible to locate very high yielding wells within the Karoo rocks. However, the water quality is questionable for drinking purposes.

The TEM investigation has revealed fundamental information about the geological structures though there remains some uncertainty as to the distribution of conductivity in the top layers. This could, however, be investigated with a smaller transmitter with a faster turn-off time and a smaller transmitter loop size.

\section{REFERENCES}

Bond, G. and MacDonald, D., 1962. The Karoo Succession at Sawmills, Southem Rhodesia, Occasional Papers of the National Museums of Southern Rhodesia, No. 26 B, pp.623-630.

Christensen, N.B., and Auken, E., 1992: SELMA - Simultaneous electromagnetic layered modeling and analysis. In: Jacobsen, B.H. (ed.): Proceedings of Interdisciplinary Inversion Workshop 1 Aarhus 1992, Methodology and Applications within Geophysics, Astronomy, and Geodesy. GeoSkrifter, Aarhus University, 41, 49-56.

Harrison, N.M., 1977. The Karoo Succession at Tjolotjo, Nyamandhlovu District, Ann. Rhodesia geol. Surv., vol 3, pp. 41-50.

MacDonald, D., 1970. The Development of Railway Borehole Water Supplies on the Bulawayo-Dette Section since 1950, The Rhodesia Science News Vol. 4, No. 12 December, 1970, pp. 398-406.

Owen, R., 1995, for Sweco, Pre-Feasibility Study of the Matabeleland-Zambezi Water Pipeline: Groundwater Study, Technical Report No: 12, 35 p.

Stagman, J.G., 1978: An Outline of the Geology of Rhodesia, Rhodesia Geological Survey, Bulletin No. 80, 126 p. 